\title{
MG132 reverse the malignant characteristics of hypopharyngeal cancer
}

\author{
JUKE MA ${ }^{1}$, LIANG YU ${ }^{1}$, JIAJUN TIAN ${ }^{1}$, YAKUI MU ${ }^{1}$, ZHENGHUA LV ${ }^{1}$, \\ JIDONG ZOU ${ }^{1}$, JIANFENG LI ${ }^{2}$, HAIBO WANG ${ }^{1}$ and WEI XU ${ }^{1}$ \\ ${ }^{1}$ Department of Otolaryngology-Head and Neck Surgery, Provincial Hospital Affiliated to Shandong University, \\ Jinan, Shandong 250021; ${ }^{2}$ Institute of Eye and Otolaryngology, Shandong Clinic Research Institute, \\ Jinan, Shandong 250022, P.R. China
}

Received September 3, 2013; Accepted March 6, 2014

DOI: $10.3892 / \mathrm{mmr} .2014 .2103$

\begin{abstract}
In order to reverse the malignant characteristics of hypopharyngeal cancer, the proteasome inhibitor MG132 was introduced into FaDu/T cells and the mechanisms underlying its effects were investigated. The multi-drug resistance (MDR) sensitivities of FaDu/T and FaDu/T-MG132 cancer cells to several chemotherapeutics were investigated by a 3-[4,5-dimethylthiazol-2-yl]-2,5 diphenyltetrazolium bromide (MTT) assay. Apoptosis was measured by staining cells with Annexin V and propidium iodide (PI) double staining. Reverse transcription-polymerase chain reaction and western blot analysis were conducted to detect mRNA and corresponding protein levels of the MDR- and apoptosis-related genes P-glycoprotein (P-gp), caspase-3, Bcl-2 and Bax. The nuclear protein of nuclear factor $\kappa$-light-chain-enhancer of activated B cells. (NF- $\kappa \mathrm{B})$ and p53 were also investigated via western blot analysis. Compared with $\mathrm{FaDu} / \mathrm{T}$ cells, the drug resistance of $\mathrm{FaDu} / \mathrm{T}+\mathrm{MG} 132$ cells to cisplatin (DDP), 5-fluorouracil (5-FU), doxorubicin (Dox) and vincristine (VCR) decreased. With increased expression of caspase- 3 and Bax and decreased expression of Bcl-2, the anti-apoptotic ability markedly decreased in FaDu/T + MG132 cells. P-gp and NF- $\kappa$ B significantly decreased; however, p53 increased in FaDu/T + MG132 cells. These results suggested that the proteasome inhibitor MG132 reversed the malignant characteristics of $\mathrm{FaDu} / \mathrm{T}$ by enhancing apoptosis and inhibiting P-gp. MG132 was also able to inhibit the nuclear translocation of NF- $\kappa \mathrm{B}$ and increase the expression of $\mathrm{p} 53$.
\end{abstract}

Correspondence to: Dr Wei Xu, Department of Otolaryngology-Head and Neck Surgery, Provincial Hospital Affiliated to Shandong University, 324 Jing Wu Road, Jinan, Shandong 250021, P.R. China

E-mail: xwhns@aliyun.com

Key words: FaDu, MG132, multidrug resistance, nuclear factor- $\kappa \mathrm{B}$, p53

\section{Introduction}

Due to the concealed location of onset and a lack of clear symptoms in the early stages, the majority of hypopharyngeal carcinoma patients are in the advanced stage when diagnosed and this results in substantial morbidity and mortality (1). The traditional treatment option for terminal hypopharyngeal carcinoma is surgical resection (2). This strategy, however, has evolved from the point of view of pure treatment to maximize preservation of hypopharyngeal function, placing emphasis upon the quality of life of these patients. Consequently, the standard approach for the treatment of these patients is radiotherapy and chemotherapy (3). Taxol or cisplatin (DDP) are used for treatment. However, chemoresistance and anti-apoptotic characteristics of cancer cells are a major obstacle for effective chemotherapy. A study has demonstrated that several molecules, including ATP-binding cassette (ABC) genes and anti-apoptotic-associated proteins have lead to the development of the multi-drug resistance (MDR) phenotype of cancer cells. The expression of $\mathrm{ABC}$ transporters and anti-apoptotic proteins result in an ATP-driven efflux of antitumor drugs from the interior of cancer cells and thereby led to decreased intracellular drug accumulation and failure to induce apoptosis (4).

To reverse these malignant characteristics, a substantial amount of effort has been dedicated to developing novel drugs. In recent years, increased attention has been paid to the proteasome pathway, which is crucial in the regulation of the cell cycle, differentiation and apoptosis in a number of normal cellular processes (5). Several studies have investigated the potential anticancer capacity of proteasome inhibitors in vitro and in vivo. As a strong proteasome inhibitor, MG132 has been verified to downregulate the MDR protein $\mathrm{P}$-glycoprotein (P-gp) and anti-apoptotic protein Bcl-2 (6). Furthermore, it is also able to increase the expression of apoptosis-related proteins Bax and caspase-3 $(7,8)$. This has warranted further investigation of MG132. However, at present, the mechanisms underlying the effect of MG132 remain largely unknown, particularly in head and neck squamous cell carcinoma (HNSCC). In the present study, , to the best of our knowledge, MG132 was introduced for the first time into the FaDu/T hypopharyngeal cancer cell line, established by exposing hypopharyngeal carcinoma $\mathrm{FaDu}$ cell lines to escalating concentrations of Taxol $(\mathrm{FaDu} / \mathrm{T})$ as 
demonstrated in our previous study (9). In addition, the present study aimed to determine whether MG132 is able to further reverse malignant behavior, including MDR and anti-apoptotic characteristics.

\section{Materials and methods}

Materials. The FaDu human hypopharyngeal carcinoma cell line was obtained from the American Type Culture Collection (Manassas, VA, USA). The media and serum were purchased from Gibco-BRL (Carlsbad, CA, USA). The chemotherapeutic drugs DDP, 5-fluorouracil (5-FU), doxorubicin (Dox) and vincristine (VCR) were purchased from Sigma (St. Louis, MO, USA). Primary antibodies, including anti-MDR1/P-gp, anti- $\beta$-actin, anti-nuclear factor $\kappa$-light-chainenhancer of activated B cells (NF- $\kappa \mathrm{B})$, anti-p53 and anti-lamin A were all purchased from Santa Cruz Biotechnology, Inc. (Santa Cruz, CA, USA). All other agents were obtained from Sigma.

Cell culture and the establishment of the resistant cell line $\mathrm{FaDu} / \mathrm{T}$. FaDu cells were cultured as a monolayer in Dulbecco's modified Eagle's medium (Gibco-BRL) containing 10\% fetal calf serum (Gibco-BRL), $100 \mathrm{U} / \mathrm{ml}$ penicillin (Sigma) and $100 \mathrm{mg}$ streptomycin (Sigma) at $37^{\circ} \mathrm{C}$ in a humidified atmosphere composed of $95 \%$ air and $5 \% \mathrm{CO}_{2}$.

The establishment methods of the resistant cell line $\mathrm{FaDu} / \mathrm{T}$ have been previously described (9).

Cytotoxicity test. A 3-[4,5-dimethylthiazol-2-yl]-2,5 diphenyltetrazolium bromide (MTT) assay was employed to assess the drug resistance sensitivities of $\mathrm{FaDu} / \mathrm{T}-200 \mathrm{nM}$ (resistant cell line $\mathrm{FaDu} / \mathrm{T}$ with a tolerance to Taxol of $200 \mathrm{nM}$ ). FaDu, $\mathrm{FaDu} / \mathrm{T}$ and $\mathrm{FaDu} / \mathrm{T}+\mathrm{MG} 32$ cells were diluted at a density of $15 \times 10^{4} / \mathrm{ml}$, subcultured in 96-well plates (Corning Inc., Corning, NY, USA) and treated with different concentrations of Dox, VCR, 5-FU and DDP for $72 \mathrm{~h}$. MTT ( $5 \mathrm{mg} / \mathrm{ml} ; 20 \mu \mathrm{l})$ was added to each well $4 \mathrm{~h}$ prior to the indicated time points. Following $4 \mathrm{~h}$ of incubation at $37^{\circ} \mathrm{C}$, the medium was removed and the precipitate was dissolved in dimethylsulfoxide. Then, optical density (OD) values were measured at $570 \mathrm{~nm}$ using an ELISA reader (Multiskan MK3; Thermo Labsystem, Waltham, MA USA). The relative viabilities of cells were calculated according to the following formula: Cell relative viability $(\%)=\mathrm{OD}_{\text {experimen }}$ ${ }_{\mathrm{t}} / \mathrm{OD}_{\text {control }}$ X 100 (OD $_{\text {blank }}$ was used as the control). The $\mathrm{IC}_{50}$ was defined as the concentration required to decrease the relative viabilities of cells to $50 \%$ of that of the control (no drug) value.

Reverse transcription-polymerase chain reaction (RT-PCR). Total RNA was extracted using TRIzol reagent (Invitrogen Life Technologies, Carlsbad, CA, USA). The reverse transcription reaction was performed using the ExScript RT reagent kit (Takara Bio, Inc., Dalian, China) in a final volume of $20 \mu \mathrm{l}$ containing $1 \mu \mathrm{g}$ of total RNA, $4 \mu \mathrm{l}$ of $5 \mathrm{X}$ ExScript buffer, $1 \mu \mathrm{l}$ dNTP mixture, $1 \mu 1$ Oligo(dT) primer, $0.5 \mu 1$ ExScript RTase, $0.5 \mu 1$ RNase inhibitor and RNase-free water to reach a volume of $20 \mu \mathrm{l}$. The reverse transcription reaction was performed at $42^{\circ} \mathrm{C}$ for $15 \mathrm{~min}$ and the reaction was terminated by heating at $95^{\circ} \mathrm{C}$ for $2 \mathrm{~min}$. PCR was performed according to the manufacturer's instructions of Takara TaqTM under the following conditions: Pre-degeneration at $95^{\circ} \mathrm{C}$ for $3 \mathrm{~min}$, degeneration at $95^{\circ} \mathrm{C}$ for $60 \mathrm{sec}$, renaturation at $58^{\circ} \mathrm{C}$ for $45 \mathrm{sec}$ and elongation at $72^{\circ} \mathrm{C}$ for $60 \mathrm{sec}$, for a total of 25 cycles. All the experiments were conducted three times. The primers used were as follows: Forward: 5'-CTGCTCAAGTTAAAGGGGCTAT-3' and reverse: 5'-AACGGTTCGGAAGTTTTCTATT-3' for ABCB1/ P-gp; forward: 5'-GCTACGAGTGGGATACTGGAGA-3' and reverse: 5'-AGTCATCCACAGAGCGATGTT-3' for Bcl-2; forward: 5'-TCATCCAGGATCGAGCAGA-3' and reverse: 5'-AAAGTAGAAGAGGGCAACCAC-3' for Bax; forward: 5'-TTTGGAACGGACCTGT-3' and reverse: 5'-CACGGGATCTGTTTCTTTGC-3' for caspase-3; and forward: 5'-GTGGGGCGCCCCAGGCACCA-3' and reverse: 5'-CTCCTTAATGTCACGCACGATTT-3' for actin.

Western blot analysis. Total protein was extracted using radioimmune precipitation protein lysis buffer according to the Protein Extraction Technology Guide. Nuclear proteins were solubilized and then fractionated by sodium dodecyl sulfate-polyacrylamide gel electrophoresis.

The Bradford method was used to determine the protein concentration of the supernatant. The samples (40 $\mu \mathrm{g}$ of each total protein) were used for western blot analysis with the primary antibodies (P-gp, 1:400, mouse anti-human; Bcl-2, 1:400 mouse anti-human; Bax, 1:400, rabbit anti-human; caspase-3, 1:400, rabbit anti-human; actin, 1:2000, mouse antihuman; NF-кB, 1:200, rabbit anti-human; p53, 1:200, mouse anti-human and lamin A, 1:200 rabbit anti-human). The bands of P-gp, Bcl-2, Bax, caspase-3, NF- $\mathrm{B}$, p53, lamin A and actin were visualized at apparent molecular weights of 170, 26, 23, 32, 53, 76 and $43 \mathrm{kDa}$, respectively. The relative OD ratio was calculated from three experiments by comparison with actin with NIH software Image J (National Institutes of Health, Bethesda, MD, USA).

Flow cytometric analysis for cell apoptosis. For apoptosis assessment, Annexin V-fluorescein isothiocyanate (FITC) and propidium iodide (PI) were used. Following trypsinization, cells were resuspended in binding buffer $(20 \mu \mathrm{l})$ containing Annexin V-FITC $(5 \mu \mathrm{l} ; 20 \mu \mathrm{g} / \mathrm{ml})$ and PI $(10 \mu \mathrm{l} ; 20 \mu \mathrm{g} / \mathrm{ml})$ for at least $10 \mathrm{~min}$ at room temperature, and then binding buffer $(300 \mu \mathrm{l})$ was added prior to analysis with system II, version 3.0 software (Beckman Coulter, Miami, FL, USA).

Statistical analysis. Data are presented as the mean \pm standard error of the mean. Statistical calculations were performed using the SPSS 16.0 software package (SPSS Inc., Chicago, IL, USA). One-way analysis of variance was applied for analysis. $\mathrm{P}<0.05$ was considered to indicate a statistically significant difference.

\section{Results}

Establishment of the taxol-resistant cell line FaDu/T and cross-resistance profiles. As reported in our previous study, $\mathrm{FaDu} / \mathrm{T}$ cells were constructed and had MDR characteristics in Taxol, Dox, VCR, 5-FU and DDP (9). However, this cross resistance markedly decreased when $\mathrm{FaDu} / \mathrm{T}$ cells were pretreated with MG132 for $24 \mathrm{~h}$ and the respective $\mathrm{IC}_{50}$ values were $0.22 \pm 0.03,2.52 \pm 0.28,14.79 \pm 0.16,2.07 \pm 0.23$ and $5.87 \pm 0.49 \mu \mathrm{M}$. A significant difference existed between 
Table I. $\mathrm{IC}_{50}$ (mean \pm standard deviation).

\begin{tabular}{lrrr}
\hline Chemotherapy drug & FaDu & FaDu/T & FaDu/T + MG132 \\
\hline Taxol $(\mu \mathrm{M})$ & $0.13 \pm 0.02$ & $15.32 \pm 3.22^{\mathrm{a}}$ & $0.22 \pm 0.03^{\mathrm{a}}$ \\
DDP $(\mu \mathrm{g} / \mathrm{ml})$ & $2.81 \pm 0.57$ & $25.25 \pm 3.78^{\mathrm{a}}$ & $2.52 \pm 0.28^{\mathrm{a}}$ \\
$5-\mathrm{FU}(\mu \mathrm{g} / \mathrm{ml})$ & $15.85 \pm 3.61$ & $347.99 \pm 46.95^{\mathrm{a}}$ & $14.79 \pm 0.16^{\mathrm{a}}$ \\
$\operatorname{Dox}(\mu \mathrm{M})$ & $1.88 \pm 0.59$ & $59.07 \pm 9.03^{\mathrm{a}}$ & $2.07 \pm 0.23^{\mathrm{a}}$ \\
$\operatorname{VCR}(\mu \mathrm{M})$ & $6.70 \pm 2.31$ & $66.97 \pm 4.84^{\mathrm{a}}$ & $5.87 \pm 0.49^{\mathrm{a}}$ \\
\hline
\end{tabular}

Comparison of chemosensitivity between $\mathrm{FaDu}, \mathrm{FaDu} / \mathrm{T}$ and $\mathrm{FaDu} / \mathrm{T}+\mathrm{MG132}$ cells $\left({ }^{\mathrm{a}} \mathrm{P}<0.05\right)$. DDP, cisplatin; 5-FU, 5-fluorouracil; Dox, doxorubicin; VCR, vincristine.



Figure 1. Expression of apoptosis-related proteins Bcl-2, Bax, caspase-3 and multi-drug resistance protein P-gp in FaDu/T and FaDu/T + MG132 cell lines by western blot analysis. (A) Representative reverse transcription-polymerase chain reaction analysis of the DNA expression. (B) Graphs demonstrate the quantification of DNA bands by densitometric scanning. ${ }^{*} \mathrm{P}<0.05$, compared with that in the FaDu/T cells. P-gp, P-glycoprotein.

$\mathrm{FaDu}$ and $\mathrm{FaDu} / \mathrm{T}$ cells, and $\mathrm{FaDu} / \mathrm{T}$ and $\mathrm{FaDu} / \mathrm{T}+\mathrm{MG} 132$ cells $(\mathrm{P}<0.05$; Table I).

RNA levels of P-gp, Bcl-2, Bax and caspase-3 in FaDu/T and $\mathrm{FaDu} / \mathrm{T}+\mathrm{MG} 132$ cells. Compared with FaDu/T cells, P-gp and Bcl-2 were downregulated in FaDu/T + MG132 cells. However, the apoptosis-related genes Bax and caspase-3, were upregulated. Image $\mathbf{J}$ software was used to analyze the relative photo density, using actin as a standard. Considering $\mathrm{FaDu} / \mathrm{T} / \mathrm{actin}$ as 100 , the relative photo densities of the $\mathrm{FaDu} / \mathrm{T}+\mathrm{MG} 132$ group was as follows: P-gp/actin, 21.51 \pm 0.83 ; Bcl-2/actin, 38.89 \pm 2.96 ; caspase-3/actin, 733.52 \pm 79.29 and Bax/actin, 271.28 \pm 29.59 . Statistical analysis demonstrated that there was a significant difference in the levels of all of
A

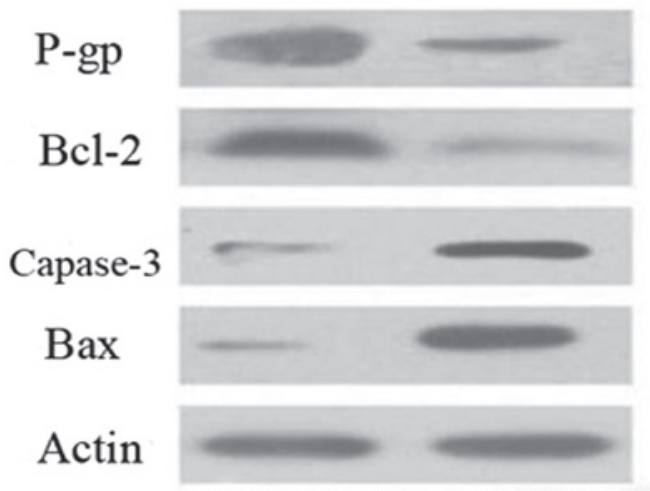

$\mathrm{FaDu} / \mathrm{T} \quad \mathrm{FaDu} / \mathrm{T}+\mathrm{MG} 132$

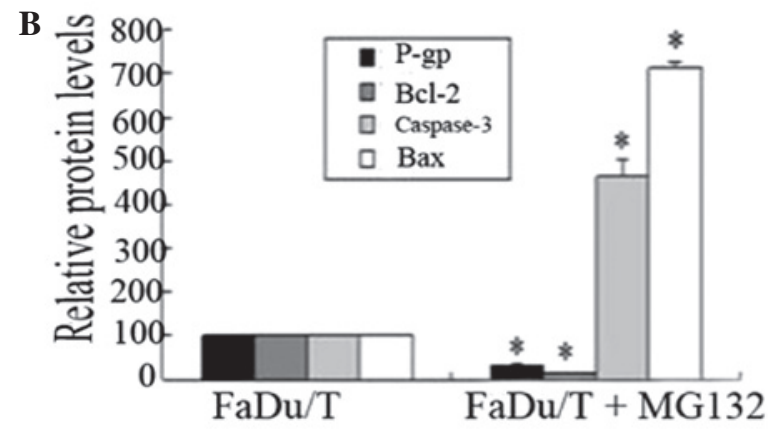

Figure 2. Expression of apoptosis-related proteins Bcl-2, Bax, caspase- 3 and multi-drug resistance protein $\mathrm{P}-\mathrm{gp}$ in $\mathrm{FaDu} / \mathrm{T}$ and $\mathrm{FaDu} / \mathrm{T}+\mathrm{MG} 132$ cell lines by western blot analysis. (A) Representative western blot analysis of the protein expression. (B) Graphs demonstrate the quantification of protein bands by densitometric scanning. " $\mathrm{P}<0.05$, compared with that in the $\mathrm{FaDu} / \mathrm{T}$ cells. P-gp, P-glycoprotein.

these proteins between $\mathrm{FaDu} / \mathrm{T}$ and $\mathrm{FaDu} / \mathrm{T}+\mathrm{MG} 132$ cells $(\mathrm{P}<0.05$; Fig. 1).

Protein levels of P-gp, Bcl-2, Bax and caspase-3 in FaDu/T and $\mathrm{FaDu} / \mathrm{T}+\mathrm{MG} 132$ cells. The expression tendency of P-gp, Bcl-2, Bax and caspase-3 protein levels was the same as the gene levels. Image $\mathbf{J}$ software was used to analyze the relative photo density, using actin as the standard. Considering $\mathrm{FaDu} / \mathrm{T} / \mathrm{actin}$ as 100 , the relative photo densities of the FaDu/T + MG132 groups were: P-gp/actin, 33.73 \pm 3.67 ; Bcl-2/actin, 16.19 \pm 0.13 ; caspase-3/actin, $464.01 \pm 38.38$ and Bax/actin, $712.99 \pm 13.28$, respectively. Statistical analysis demonstrated that there was a significant difference between $\mathrm{FaDu} / \mathrm{T}$ and FaDu/T + MG132 cells ( $\mathrm{P}<0.05$; Fig. 2). 

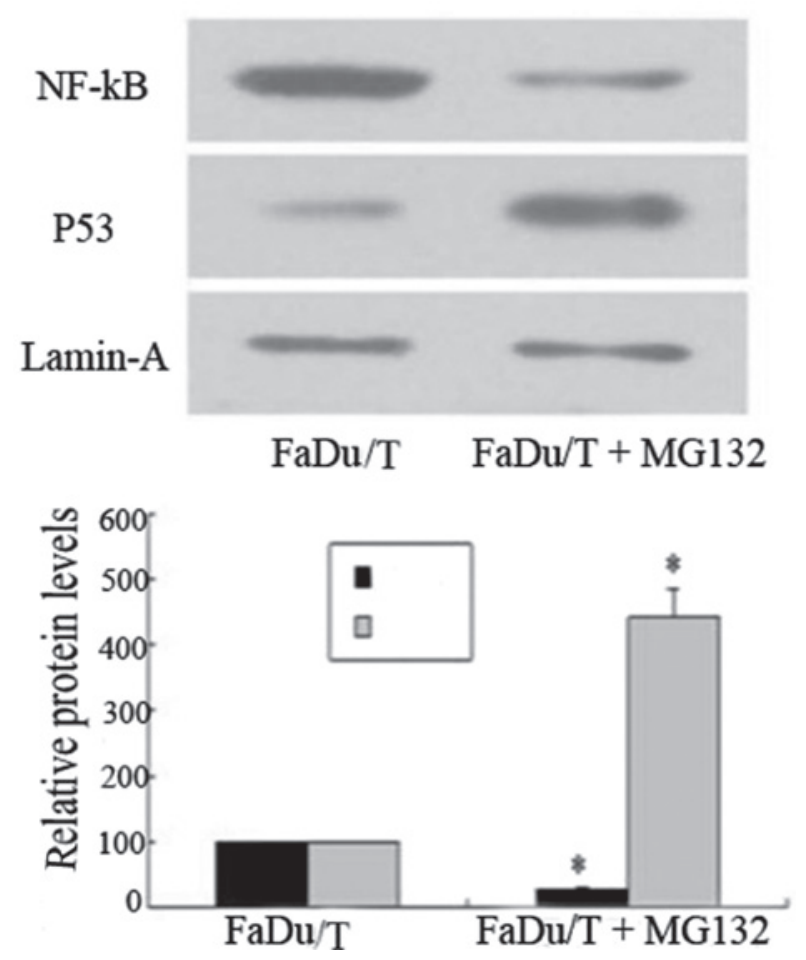

Figure 3. Effect of MG132 treatment on the expression of NF- $\kappa \mathrm{B}$ and $\mathrm{p} 53$ in $\mathrm{FaDu} / \mathrm{T}$ cell lines by western blot analysis. Compared with $\mathrm{FaDu} / \mathrm{T}$ cell lines, the nuclear translocation of $\mathrm{NF}-\kappa \mathrm{B}$ in $\mathrm{FaDu} / \mathrm{T}+\mathrm{MG132}$ cells lines markedly decreased; however, p53 demonstrated the opposite effect ${ }^{*} \mathrm{P}<0.05$, compared with that in the FaDu/T cells. NF- $\kappa \mathrm{B}$, nuclear factor $\kappa$-light-chain-enhancer of activated B cells.


Figure 4. Effect of MG132 treatment on the expression of different apoptotic ratios in $\mathrm{FaDu} / \mathrm{T}$ cell lines by flow cytometry.

$M G 132$ inhibits the nuclear translocation of $N F-\kappa B$, however, increases the expression of p53 in FaDu/T cells. Compared with $\mathrm{FaDu} / \mathrm{T}$ cells, the nuclear protein levels of $\mathrm{NF}-\kappa \mathrm{B}$ expressed in the FaDu/T + MG132 cells increased whereas the p53 levels decreased. Lamin A was used as the standard. Considering $\mathrm{FaDu} / \mathrm{T} / \mathrm{lamin} \mathrm{A}$ as 100 , the relative photo densities of $\mathrm{FaDu} / \mathrm{T}+\mathrm{MG} 132 /$ lamin $\mathrm{A}$ in $\mathrm{NF}-\kappa \mathrm{B}$ and $\mathrm{p} 53$ were $29.00 \pm 2.35$ and $441.48 \pm 42.00$, respectively. Statistical analysis demonstrated that there was a significant difference between FaDu/T and FaDu/T + MG132 cells ( $\mathrm{P}<0.05$; Fig. 3).
Different proportions of apoptotic cells between FaDu/T and $\mathrm{FaDu} / T+M G 132$ cells. To assess the apoptotic induction capacity of MG132, FaDu/T cells were treated with MG132 for $24 \mathrm{~h}$ and the proportions of apoptotic cells were investigated. Compared with the apoptotic rate of $\mathrm{FaDu} / \mathrm{T}$ cells $(4.45 \pm 1.60 \%)$, the rate in cells exposed to MG132 was $32.9 \pm 2.39 \%$. These results indicated that MG132 has a more potent apoptotic induction capacity in $\mathrm{FaDu} / \mathrm{T}$ cells (Fig. 4).

\section{Discussion}

Currently, the standard approach of advanced HNSCC treatment, particularly hypopharyngeal carcinoma, is surgery combined with radiotherapy and chemotherapy. In terms of chemotherapy, MDR of cancer cells has always been a major problem in treatment. To further investigate the MDR reversal of hypopharyngeal cancer cells, based on the established MDR hypopharyngeal carcinoma cell line FaDu/T, MG132 was introduced into $\mathrm{FaDu} / \mathrm{T}$ cells and the internal mechanisms of the effects of MG132 were investigated.

Our previous study demonstrated that, compared with FaDu cells, the expression of the MDR protein P-gp and anti-apoptotic protein Bcl-2 markedly increased in $\mathrm{FaDu} / \mathrm{T}$ cell lines, whereas the apoptosis-related proteins caspase- 3 and Bax decreased. P-gp, encoded by the multi-drug resistance 1 (MDR1) gene, is an efflux transporter, which is important in the MDR of cancer cells and transports numerous substrates, including Taxol and VCR. As an anti-apoptotic member of the Bcl family, Bcl-2 inhibits the release of apoptotic molecules, including the caspase family members, by interacting with Bax (10). The increased expression of P-gp and Bcl-2 appears to be a critical factor of chemotherapy and apoptosis resistance in $\mathrm{FaDu} / \mathrm{T}$ cells. In order to overcome the malignant behavior of $\mathrm{FaDu} / \mathrm{T}$ tumor cells, numerous chemotherapeutic drugs have been demonstrated to be effective in vivo; however, the toxicity and side effects largely limit the clinical application over a long period. The results of previous in vitro trials indicate that the proteasome inhibitor MG132 is a potent P-gp inhibitor and apoptosis inducer in several types of tumor cells (11). To verify whether MG132 has the ability to reverse the MDR and anti-apoptotic properties of $\mathrm{FaDu} / \mathrm{T}$ cells, experiments were performed based on the previous study. With the addition of MG132 to FaDu/T cells, P-gp was markedly decreased, Bcl-2/Bax began to decrease and caspase- 3 increased. The data from assays indicated that MG132 is able to markedly reverse the malignant behavior of $\mathrm{FaDu} / \mathrm{T}$ cells. However, the molecular mechanisms underlying the effects of MG132 require further investigation.

As a promising proteasome inhibitor, MG132 is able to induce a range of antitumor activity, including the restoration of sensitivity to chemotherapy and provocation of apoptosis (12). It has been reported that MG132 exerts these functions through inhibiting the degradation of $\mathrm{I} \kappa \mathrm{B}$ proteins and therefore suppresses the nuclear translocation and activation of $\mathrm{NF}-\kappa \mathrm{B}$ (13). As an important transcription factor, the activation state of $\mathrm{NF}-\kappa \mathrm{B}$ positively regulates the expression of P-gp and $\mathrm{Bcl}-2$ in cancer cells, as a binding site for $\mathrm{NF}-\kappa \mathrm{B}$ exists in the P-gp and Bcl-2 promoter region $(14,15)$. Several studies have indicated that $\mathrm{p} 53$, a transcription factor, is able to induce the expression of the apoptotic factor Bax, which is also one of the most commonly mutated genes in HNSCC (16). As the substrate 
of the proteasome, the degradation of p53 may also be inhibited by MG132 (17). As the present study demonstrated, when MG132 was added to FaDu/T cells, the nuclear translocation of $\mathrm{NF}-\kappa \mathrm{B}$ and the degradation of p53 were all inhibited and consequently the expression of P-gp and Bcl-2 decreased. In addition, the expression of the apoptosis-related proteins Bax and caspase- 3 was markedly upregulated when $\mathrm{FaDu} / \mathrm{T}$ cells were treated with MG132. For caspase-3, certain studies have indicated that MG132 is able to cause mitochondrial dysfunction and subsequently cause cytochrome $C$ release, which results in the activation of caspase- 3 and caspase-dependent apoptotic processes (8).

To further investigate the apoptotic state of $\mathrm{FaDu} / \mathrm{T}$ cells affected by MG132, flow cytometry was conducted and it was revealed that MG132 is able to significantly increase the apoptotic ratio compared with $\mathrm{FaDu} / \mathrm{T}$ cells. Additionally, in terms of MDR, the present study also revealed that the multi-drug resistance of FaDu/T cells to DDP, 5-FU, Dox and VCR was markedly decreased when treated with MG132. This involved the reduction of $\mathrm{P}$-gp and $\mathrm{Bcl}-2$ accompanied by the upregulation of Bax and caspase-3, and led to apoptosis of the majority of $\mathrm{FaDu} / \mathrm{T}$ cells.

In conclusion, these observations indicated that the upregulation of Bax and caspase-3 were involved in MG132-induced apoptosis in the $\mathrm{FaDu} / \mathrm{T}$ cancer cell line. In addition, decreased $\mathrm{P}-\mathrm{gp}$ and $\mathrm{Bcl}-2$ levels were observed in $\mathrm{FaDu} / \mathrm{T}$ cancer cells treated with MG132. The mechanisms underlying the effects of MG132 are based on the $\mathrm{NF}-\kappa \mathrm{B}$ and p53 pathways. All the alterations in apoptosis and drug resistance relative genes are beneficial for MG132 to reverse MDR in FaDu/T cells. These results may be valuable for the prevention of MDR and anti-apoptosis derived from cancer cells in clinical cancer chemotherapy.

\section{Acknowledgements}

This study was supported by the Shandong Provincial Outstanding Young Scientist Research Award Fund of China (grant no. BS2009YY013) and the Shandong Provincial International Science and Technology Cooperation Project of China (grant no. 2010GHZ20202).

\section{References}

1. Bok GH, Cho WY, Cho JY, et al: Endoscopic resection of hypopharyngeal squamous cell carcinoma. Clin Endosc 46: 189-192, 2013.
2. Clark JI, Hofmeister C, Choudhury A, et al: Phase II evaluation of paclitaxel in combination with carboplatin in advanced head and neck carcinoma. Cancer 92: 2334-2340, 2001.

3. Yoshino T, Hasegawa Y, Takahashi S, et al: Platinum-based chemotherapy plus cetuximab for the first-line treatment of Japanese patients with recurrent and/or metastatic squamous cell carcinoma of the head and neck: results of a phase II trial. Jpn J Clin Oncol 43, 524-531, 2013.

4. Rodrigues AC, Curi R, Genvigir FD, et al: The expression of efflux and uptake transporters are regulated by statins in Caco-2 and HepG2 cells. Acta Pharmacol Sin 30: 956-964, 2009.

5. Ludwig H, Khayat D, Giaccone G, et al: Proteasome inhibition and its clinical prospects in the treatment of hematologic and solid malignancies. Cancer 104: 1794-1807, 2005.

6. Wang W and Luo HS: Reversal of chemoresistance to vincristine in gastric cancer cells by NF-kappaB inhibitor. Zhonghua Zhong Liu Za Zhi 27: 335-338, 2005 (In Chinese).

7. Fan XM, Wong BC, Wang WP, et al: Inhibition of proteasome function induced apoptosis in gastric cancer. Int J Cancer 93: 481-488, 2001.

8. Westerberg CM, Hägglund H and Nilsson G: Proteasome inhibition upregulates Bim and induces caspase-3-dependent apoptosis in human mast cells expressing the Kit D816V mutation. Cell Death Dis 3: e417, 2012.

9. Ma J, Lu S, Yu L, et al: FaDu cell characteristics induced by multidrug resistance. Oncol Rep 26: 1189-1195, 2011.

10. Youle RJ, Strasser A. The BCL-2 protein family: opposing activities that mediate cell death. Nat Rev Mol Cell Biol 9: 47-59, 2008.

11. Chen YC, Huang WJ, Hsu JL, et al: A novel hydroxysuberamide derivative potentiates MG132-mediated anticancer activity against human hormone refractory prostate cancers - the role of histone deacetylase and endoplasmic reticulum stress. Prostate 73: 1270-1280, 2013.

12. Bravo-Cuellar A, Hernández-Flores G, Lerma-Díaz JM, et al: Pentoxifylline and the proteasome inhibitor MG132 induce apoptosis in human leukemia U937 cells through a decrease in the expression of Bcl-2 and Bcl-XL and phosphorylation of p65. J Biomed Sci 20: 13, 2013.

13. Wang Y, Sun W, Du B, et al: Therapeutic effect of MG-132 on diabetic cardiomyopathy is associated with its suppression of proteasomal activities: roles of Nrf2 and NF- $\kappa \mathrm{B}$. Am J Physiol Heart Circ Physiol 304: H567-H578, 2013.

14. da Silva SV, Salama C, Renovato-Martins M, et al: Increased leptin response and inhibition of apoptosis in thymocytes of young rats offspring from protein deprived dams during lactation. PLoS One 8: e64220,2013.

15. Kanagasabai R, Krishnamurthy K, Druhan LJ, et al: Forced expression of heat shock protein 27 (Hsp27) reverses P-glycoprotein (ABCB1)-mediated drug efflux and MDR1 gene expression in Adriamycin-resistant human breast cancer cells. J Biol Chem 286: 33289-33300, 2011.

16. Chen Y, Zhang X, Dantas Machado AC, et al: Structure of p53 binding to the BAX response element reveals DNA unwinding and compression to accommodate base-pair insertion. Nucleic Acids Res 41: 8368-8376, 2013.

17. Pigneux A, Mahon FX, Moreau-Gaudry F, et al: Proteasome inhibition specifically sensitizes leukemic cells to anthracyclin-induced apoptosis through the accumulation of Bim and Bax proapoptotic proteins. Cancer Biol Ther 6: 603-611, 2007. 